\title{
Prevalence Study of Psychiatric Disorders among Female Prisoners due to Violence Crimes
}

\author{
Mohamed M. elmeligi ${ }^{1 *}$, M.B.B.CH; Adel M. elmedany², MD; Mohamed H. Bahry ${ }^{2}$, MD; Mohamed E. \\ Ramadan $^{2}, \mathrm{MD}$
}

*Corresponding Author:

Mohamed M. elmeligi

meligimohamed@yahoo.com

Received for publication

March 10, 2020; Accepted

Mayh 14, 2020; Published

online June 6, 2020.

Copyright 2020 The Authors published by Al-Azhar University, Faculty of Medicine, Cairo, Egypt. All rights reserved. This an openaccess article distributed under the legal terms, where it is permissible to download and share the work provided it is properly cited. The work cannot be changed in any way or used commercially.

doi:

10.21608/aimj.2020.24181.1148

1* Department of Psychiatry Police Hospitals - Ministry of Interior.

${ }^{2}$ Department of Psychiatry Faculty of Medicine - Al-

Azhar University.
ABSTRACT

Background: About 9 million people are imprisoned worldwide, but the number of mental disorders is unknown.

Aim of the study: Determination of the prevalence of psychiatric disorders among female prisoners of violent crimes inside one of the Egyptian prisons.

Patient and Method: The study was done on 134 female prisoners in Tanta General Prison, in a certain period " Aug.2014 - Jun.2015". Instruments and procedures: First all the samples were examined with semi-structured interviews by the researcher and diagnosed according to DSM IV TR. Then the sample had three questionnaires, ( Ezynk - IQ Family Economic Social Cultural Level). These data underwent statistical analysis, and then the researcher described them in tables to correlate between the socio-demographic, clinical variables, and questionnaires of the study.

Results: The results of the semi-structured interview had revealed that the majority of the sample were suffering from psychiatric disorders with percentage represented $(61.9 \%)$. The most common disorders were substance abuse (35.07\%), histrionic personality disorder (24.6\%), major depressive disorder (17.9\%), and borderline personality disorder (15.6\%). The results of Ezynk represented that psychotic personality has been found among female violent prisoners. The results of IQ represented a marked decrease among the majority of the sample. The results of the Family Economic Social Cultural Level Questionnaire represented a marked decrease among the majority of the sample.

Conclusion: The psychiatric disorders are markedly increased among the female prisoners who were imprisoned due to violent crimes.

Keywords: Study, Psychiatric Disorders, Female Prisoners, Violence Crimes

Disclosure: The author has no financial interest to declare in relation to the content of this article. The Article Processing Charge was paid for by the author.

Authorship: All authors have contributed to the article.

\section{INTRODUCTION}

About 9 million people are imprisoned worldwide, but the number of mental disorders is unknown. Several studies of prisoners on 12 countries reported that the prevalence of psychotic illnesses between men was $3.7 \%$ and between women was $4.0 \%$, prevalence of depression between men was $10 \%$ and between women was $12 \%$, and prevalence of personality disorders between men was $65 \%$ and between women $42 \%{ }^{1}$.

In a study of the psychological and sociological profiles of 95 female offenders in Mansoura General Prison, the prevalence of depression was $25.26 \%$, prevalence of anxiety was $9.38 \%$, and prevalence of personality disorders was $55.79 \%{ }^{2}$.

Crime is considered a violent phenomenon in all its phases, so, it was a superstition that it is more likely suitable for males, who can afford and perform it better than females in both quality and quantity ${ }^{3}$.

Forensic psychiatry is the science that vestigates the relationships between psychiatry and medicine, so it gets down to crimes and its phases according to the psychological aspect. Although the psychiatric patients represent the minor percentage between offenders, they cause a lot of difficulties for psychiatry and law due to the relationship between psychiatric disorders and crimes which affects judgment 4 .

Researchers should exert more effort to study the factors of committing crimes because there are a lot of difficulties that face them during researches as the missed recorded crimes ( family crimes ) ${ }^{5}$. 
The studies which concern with antisocial behavior shows significant differences according to quantity and quality between males and females so that the forensic psychiatry decided the possibility of differences in causes and methods of crimes between genders ${ }^{6}$.

The forensic psychiatry studied the prevalence of crimes and its relationships to psychiatric disorders, explaining that the psychiatric disorders are not the main cause of crimes even if the offender was a psychiatric patient ${ }^{7}$. The substance abuse had a great relationship to different crimes because alcohol and drugs play a great role in the elevating the prevalence of crimes, the study of offenders due to violent crimes in Sweden showed that $16 \%$ of them had a past history of addiction ${ }^{8}$.

Although the varieties between psychiatric disorders and crimes, violent crimes have a great relationship to personality disorders especially antisocial personality disorder, paranoid schizophrenia, and substance abuse ${ }^{9}$ Objectives This study aimed to determine the prevalence of psychiatric disorders among female prisoners of violent crimes inside one of the Egyptian prisons.

\section{PATIENT AND METHODS}

The study was done in Tanta General Prison, in a certain period "from Aug.2014 till Jan.2015". The sample size of the study was 134 female prisoners who were imprisoned due to violent crimes. All the samples of the study are Egyptians, healthy, and stayed more than a year in prison.

Instruments and procedures:-First all the samples were examined with a semi-structured interview by the researcher and diagnosed according to DSM IV TR .

Then the sample had three questionnaires, (Eysenck IQ - Family Economic Social Cultural Level ).

These data underwent statistical analysis, and then the researcher described them in tables to correlate between the socio-demographic, clinical variables, and questionnaires of the study.

\section{RESULTS}

The results of the study revealed that $(61.9 \%)$ represented with psychiatric disorders.

\begin{tabular}{|c|c|c|}
\hline Diagnosis & no. & $\%$ \\
\hline Substance abuse & 47 & 35.07 \\
\hline Histrionic personality disorder & 33 & 24.6 \\
\hline Major depressive disorder & 24 & 17.9 \\
\hline Borderline personality disorder & 21 & 15.6 \\
\hline Antisocial personality disorder & 15 & 11.1 \\
\hline Generalized anxiety disorder & 13 & 9.7 \\
\hline Sleep disorder & 10 & 7.4 \\
\hline Borderline disorder & 9 & 6.7 \\
\hline panic & 8 & 5.9 \\
\hline Social phobia & 8 & 5.9 \\
\hline Obsessive compulsive disorder & 7 & 5.2 \\
\hline Schizophrenia & 4 & 2.9 \\
\hline Total no. & 134 & $\% 100$ \\
\hline
\end{tabular}

Table 1: Psychiatric disorders according to DSM5. 
The most common disorders were substance abuse (35.07\%), histrionic personality disorder (24.6\%), major depressive disorder (17.9\%), and borderline personality disorder (15.6\%). The Dual diagnosis represents the majority of the sample. The percentage of psychiatric disorders were markedly elevated among the age group (3039) year old.

\begin{tabular}{|c|c||c|}
\hline Personalities & No. & \% \\
\hline \hline Introversion & 45 & 33.5 \\
\hline Psychoticism & 134 & 100 \\
\hline Neuroticism & 97 & 72.3 \\
\hline Lie-social desirability & 15 & 11.2 \\
\hline Criminal aptitude & 134 & 100 \\
\hline \hline Total & $\mathbf{1 3 4}$ & $\mathbf{1 0 0}$ \\
\hline
\end{tabular}

Eysenck personality questionnaire.

According to the results of Eysenck, the psychotic personality represents all the sample of female violent prisoners

\begin{tabular}{|c|c|c|}
\hline scale & No. & $\%$ \\
\hline \hline extremely low(58-68) & 89 & 71.4 \\
\hline Dull(69-80) & 37 & 16.9 \\
\hline Average(81-115) & 8 & 5.9 \\
\hline Superior(116-125) & 0 & 0 \\
\hline \hline total & $\mathbf{1 3 4}$ & $\% \mathbf{1 0 0}$ \\
\hline
\end{tabular}

Table 3: IQ.

The results of IQ represents a marked decrease among the majority of the sample.

\begin{tabular}{||c|c|c|}
\hline & No. & $\%$ \\
\hline Low(580115) & 89 & $\mathbf{6 6 . 4}$ \\
\hline Average(116-173) & 45 & 33.6 \\
\hline High(174-230) & 0 & 0 \\
\hline \hline $\mathbf{1 0 0}$ & $\mathbf{1 3 4}$ & $\% \mathbf{1 0 0}$ \\
\hline
\end{tabular}

Table 4: Family Economic Social Cultural Level.

The results of the Family Economic Social Cultural Level Questionnaire represents a marked decrease among the majority of the sample.

\section{DISCUSSION}

The study was done on a sample of females who were imprisoned due to violent crimes, so it is a cohort study that its results can't be compared with the results of general population studies.

The sample was 134 female prisoners who were poisoned in Tanta general prison.

Most samples are in the age group(30-39) (median=30.9, SD=2.7), this could be due to the high 
rates of stressors that face people in this age group which is the productive period of life ${ }^{10}$.

Married represents $55.2 \%$, and this could be due to the marital pressures which may push them towards crimes 2 .

Intermediate - educated represents the majority of the sample $54.6 \%$, and this could be due to their failure to control emotions and aggression by thinking ${ }^{10}$.

The psychiatric disorders among female prisoners in violent crimes represent $61.9 \%$, so, it is very high rates compared with the general population 11 .

As regards the results of the study, the dual diagnosis represents the majority of sample ${ }^{12}$. The substance abuse disorder represents $35.07 \%{ }^{13}$,major depressive disorder $17.9 \%{ }^{14}$ and schizophrenia $2.9 \%{ }^{1}$.

According to murders, substance abuse represents $51.3 \%$, followed by major depressive disorder $40.5 \%$, then borderline personality disorder $35.1 \%$, antisocial personality disorder and bipolar $24.3 \% .^{9}$

$50 \%$ of forced robbing offenders suffered from generalized anxiety disorder and histrionic personality disorder, while substance abuse represented $44.4 \%$, panic $22.2 \%$, antisocial personality disorder $16.7 \%$, sleep disorder, and OCD $11.1 \%$.

$71.4 \%$ of the sample has an extremely low IQ level followed by dull zone $16.9 \%$, which explains the shortage of thinking and judgment ${ }^{15}$.

Finally, the majority of the sample represented by low levels on the Family Economic Social Cultural questionnaire $66.4 \%$, followed by the average level of $33.6 \%$, with no high levels at all ${ }^{10}$.

\section{CONCLUSION}

The study represents the high rates of psychiatric disorders among female offenders due to violent crimes, so the study recommends psychological and sociological studies of the causes of crimes and supports the role of psychiatrists, psychologists in prisons, especially females prisons, and increasing their numbers.

The study also recommends the aim to promote strategies for the care and rehabilitation of inmates and trying to improve the economic, social, and cultural levels of families by specific programs.

\section{REFERENCES}

1. Fazel S, and Danesh J. Serious Mental Disorders in 23000 Prisoners: systemic review of 62 surveys. The Lancet.,2002; Vol. 359, p. 545-50.

2. El-Bahaey W, El-Mansoury A.M and El-Dakroury S. Psychological and socio-demographic profile of female offenders: A study in Mansoura General Prison. Egyptian Journal of Psychiatry., 2004; Vol. 23, No. 2, p. 66-75.

3. Khalil A. Analysis of criminal phenomenon: Police academy,2012.
4. Oxford. Shorter Oxford Textbook Of Psychiatry, fifth edition, 2005.

5. Jon S and Tricia D. Crime in England and Wales: Research Development and Statistics Directorate,2003; London SW1H 9AT, United Kingdom.

6. Thalia C, Eley A, Paul L, Terrie E and Moffitt A. A longitudinal behavioral genetic analysis of the etiology of aggressive and non-aggressive antisocial behavior: Development and Psychopathology.,2003; 15: pp 383402

7. Elbogen EB and Johnson SC. The intricate link between violence and mental disorder: Forensic Psychiatry Program and Clinic,2009; Department of Psychiatry, University of North Carolina Chapel Hill School of Medicine, Chapel Hill, Feb;66(2):152-61.

8. Martin G and Seena F. Substance misuse and violent crime: Swedish population study. BMJ, 2004; 328 doi: 10.1136/bmj.328.7450.1233.

9. Richard S, Olie JP and Gourevitch R. Risk of homicide and major mental disorders: Département de psychiatrie et psychologie médicale, CHU d'Angers, 4, rue Larrey, 49933 Angers cedex 9, France. Encephale,2009; Dec;35(6):521-30.

10. Virginia D and Gabriel M. Demographic, BioPsychological and Socio-Economic Factors Associated with Recidivism at a Central Prison in Zimbabwe: JSS,2017; Vol.5 No.8.

11. Stephen G and Roger R. Women prisoners: BMJ, 2013;346:e8318 doi: 10.1136/bmj.e8318.

12. Stephanie W. Hartwell. Comparison of Offenders With Mental Illness Only and Offenders With Dual Diagnoses: Published online, 2004; |https://doi.org/10.1176/appi.ps.55.2.145

13. Steven L and Proctor M.A. Substance Use Disorder Prevalence among Female State Prison Inmates: Published online, 2012;

https://doi.org/10.3109/00952990.2012.668596

14. Edward B, Kimina C, Abhilash D and Stuart K. Prevalence of mental illness among Aboriginal and Torres Strait Islander people in Queensland prisons: MJA, 2012; 197: 37-41. doi: 10.5694/mja11.11352.

15. Mihai P. An analysis of the relation between IQ and crime in the European countries: Conference Paper, 2013;

https://www.researchgate.net/publication/258857651 